\title{
From TATA to NOTES, how taTME fits into the evolutionary surgical tree
}

\author{
J. H. Marks ${ }^{1}$ J. F. Salem ${ }^{2}$
}

Received: 14 June 2016/Accepted: 19 June 2016/Published online: 5 July 2016

(C) Springer-Verlag Italia Srl 2016

"Necessity...is the mother of... Invention." Plato

"A mind that is stretched by a new experience can

never go back to its old dimensions." Oliver Wendall

Holmes Jr.

Often an idea once planted, needs to be carefully nurtured and tended to in order to grow into a strong, vibrant being. This holds true in surgery and particularly in rectal cancer management, where perhaps more so than in any other field of oncology, oncologic outcomes and quality of life issues are so closely married. The article by Chouillard in this month's journal describing a transanal NOTES total mesorectal excision (taTME) demonstrates elegantly the seed of an idea growing into a fruitful reality.

The challenge of extirpating a low rectal cancer in the narrow confines of the bony pelvis while avoiding a permanent colostomy remains a daunting task for the surgeon. Local recurrence (LR) rates in the 20-40\% range in the 1970s-1980s [1] led to several essential advances in rectal cancer care. High-dose preoperative radiation therapy was employed to lower local failure rates [2]. Additionally, Heald heightened the focus on the primacy of proper surgical technique in the treatment of rectal cancer, coining the term total mesorectal excision (TME) and demonstrating its effect in improving LR rates [3]. During this same period, Dr Gerald Marks implemented the first

\section{J. H. Marks \\ marksj@mlhs.org}

1 Colorectal Surgery, Main Line Health System, Lankenau Medical Center, Wynnewood, PA, USA

2 Division of Colorectal Surgery, Lankenau Medical Center, Wynnewood, PA, USA program in the world of sphincter preservation surgery following high-dose preoperative radiation therapy [4]. Responding to the challenge of determining an adequate distal margin, in 1984 Dr Marks developed the technique of Transanal Abdominal TransAnal proctosigmoidectomy with coloanal anastomosis (TATA) [5]. The TATA procedure, unwittingly ushered in the era of taTME. But at this time the seed had just been placed into the soil. By starting transanally, Dr Marks postulated that a known distal margin could be safely achieved even for cancers in the distal $1 / 3$ of the rectum, if the cancer was not growing into the levators. The TATA was born from the practical necessity to obtain a reliable distal margin in a cancer that was difficult to palpate after it had been downstaged significantly from preoperative therapy. Subsequently, others have used a derivation of this approach and termed it an intersphincteric resection. However, most performing the surgery in this fashion did so by doing the TME from above, taking it as low as possible and only going below to finish the transection and do the anastomosis. Commonly when we presented our TATA work, the criticism was that it was too bothersome for the surgical team to work transanally and then go above and back below to do the anastomosis. This left the TATA procedure with several dedicated acolytes but not large-scale adoption.

As laparoscopic rectal surgery developed, questions arose which still persist today, regarding the technical difficulty of TME surgery laparoscopically. Problems with GIA stapler application and distal margins entered the discussion. In fact many surgeons still perform their rectal cancer work by doing the mobilization laparoscopically and the TME in an open fashion via a lower midline incision. Because of our referral patterns, many of the 
rectal cancers we treated were so low they required a TATA procedure. This patient population propelled me to develop a large laparoscopic rectal cancer experience. I was unencumbered in these cases to perform the problematic portions laparoscopically as the TATA procedure enveloped the distal dissection transanally to the level of the seminal vesicles or cervix. Additionally the GIA issue was irrelevant as the rectal transection and closure of the rectum had already been carried out from below. While this was something that we were aware of at the time, it was not an emphasis of our teaching or writing, as the major focus of the TATA was extending sphincter preservation and avoiding a permanent colostomy with good oncologic control. To these ends we were quite successful with a LR rate of only $2.5 \%$ and an APR rate of $7 \%$ [6]. The advantages of the minimally invasive taTME approach were not emphasized or likely even fully appreciated at the time. We did note, however, that our conversion rate of $2.5 \%$ was far lower than those reported in most trials, but we attributed this to other factors. With proper watering and sunlight, the TATA/taTME seed began to grow.

Simultaneously, another branch of the tree was developing. Natural orifice transluminal endoscopic surgery (NOTES) had been described by Kalloo as the ultimate goal in minimally invasive surgery. At the time the notion of injuring a healthy organ in order to take out a diseased one raised questions in our minds. However, the notion of performing NOTES where a target organ was the organ of entry, such as colorectal surgery, made perfect sense. During the same period, Albert, Larach and Atallah [7] described the use of a single-port device transanally, naming it TransAnal Minimally Invasive Surgery (TAMIS), which would allow laparoscopic surgery transanally. Simultaneously, we were becoming more comfortable operating and entering into the peritoneal cavity with the TEM equipment. It was only a matter of time that these different paths came together, and we performed our first extended taTME, in December of 2008, using the TEM equipment in a patient with a locally advanced cancer unresectable from above. In the spring of 2009, we performed a full proctectomy transanally using the SILS device in a Crohn's patient. By taking advantage of the pneumopelvis outside of the rectum once the TATA was performed, dissection could readily be extended proximally even entering into the abdominal cavity.

Chouillard's article in this month's journal highlights the applicability and the evolution of the TATA experience to a full blown taTME and NOTES resection. While demonstrating excellent results, their experience as well as our own highlights some of the great challenges that exist [8]. We have recently published our data demonstrating comparable pathologic outcomes of taTME compared to laparoscopic TME [9]. However, issues regarding unusual injuries particularly urethral injuries highlight the need for better training and refinement of technique. Training needs to be thorough as dissection too deeply in this field will injure the levator and the sphincter mechanism, leaving the patient incontinent. A dissection too superficial into the rectal wall will endanger proper oncologic care. Instrumentation issues exist regarding angulation, flexibility and reach. The development of instruments to allow for good visualization and retraction in the limited confines of the pelvis without sacrifice of good visualization is essential. The ability to exchange instruments while performing NOTES resection remains a continued challenge.

It does appear clear, however, that the idea of TATA/taTME resection is clearly taking a hold in the mind of rectal cancer surgeons. The ongoing challenge of dissection in the confines of the bony pelvis seems to be adequately addressed by this approach. Operating from above, the most difficult aspect of the operation is the distal most dissection. Starting the operation transanally as it is done in the taTME allows the most challenging aspect of the TME dissection to be carried out initially. This allows the surgeon to address their biggest challenge immediately, with the linear aspect of the lower third of the pelvis directly in front of them. This has proven to be quite beneficial, particularly in performing a minimally invasive TME surgery in obese patients or men with a narrow pelvis. That being said the gradual evolution of TATA/taTME approach to the full NOTES procedure represents the ultimate goal to be achieved. In the immediate term, however, taTME fosters growth of this idea in the surgical community, extending the possibilities to improve visualization, surgical outcomes and extending sphincter preservation for rectal cancer patients.

What this TATA/taTME approach ultimately grows into remains to be seen. However, with the convergence of TATA/taTME, transanal endoluminal surgery and NOTES, it appears that the seed has established strong roots and is set to grow into a substantial entity.

\section{Compliance with ethical standards}

Conflict of interest The authors declare that they have no conflict of interest.

Ethical approval All procedures performed in studies involving human participants were in accordance with the ethical standards of the institutional research committee and with the 1964 Helsinki declaration and its later amendments or comparable ethical standards.

Informed consent Informed consent was obtained from all individual participants included in the study.

\section{References}

1. Olson RM, Perencevich NP, Malcolm AW, Chaffey JT, Wilson RE (1980) Patterns of recurrence following curative resection of adenocarcinoma of the colon and rectum. Cancer 45:2969-2974 
2. Sauer R, Liersch T, Merkel S et al (2012) Preoperative versus postoperative chemoradiotherapy for locally advanced rectal cancer: results of the German CAO/ARO/AIO-94 randomized phase III trial after a median follow-up of 11 years. J Clin Oncol 30:1926

3. Heald RJ, Ryall RD (1986) Recurrence and survival after total mesorectal excision for rectal cancer. Lancet 327:1479-8210

4. Mohiuddin M, Dobelbower R, Turalba C, Kramer S, Marks G (1979) A selective sandwich technique of adjuvant radiotherapy in the treatment of rectal cancer: a preliminary experience. Dis Col Rectum 22:1-4

5. Marks G, Bannon J, Marks J (1996) Transanal-abdominal Transanal radical proctosigmoidectomy with coloanal anastomosis for distal rectal cancer. In: Baker R, Fisher J, Nyhus L (eds) Mastery of surgery, 3rd edn. Little, Brown and Company Inc, Boston, pp 1524-1534
6. Marks JH, Frenkel JL, D'Andrea AP, Greenleaf CE (2011) Maximizing rectal cancer results: TEM and TATA techniques to expand sphincter preservation. Surg Oncol Clin N Am 20:501-520

7. Albert MR, Atallah SB, deBeche-Adams TC, Izfar S, Larach SW (2013) Transanal minimally invasive surgery (TAMIS) for local excision of benign neoplasms and early-stage rectal cancer: efficacy and outcomes in the first 50 patients. Dis Colon Rectum 56:301-307

8. Marks JH, Lopez-Acevedo N, Krishnan B, Johnson MN, Montenegro GA, Marks GJ (2016) True NOTES TME resection with splenic flexure release, high ligation of IMA, and side-to-end handsewn coloanal anastomosis. Surg Endosc. doi:10.1007/s00464$015-4731-7$

9. Marks JH, Montenegro GA, Salem JF, Shields MV, Marks GJ (2016) Transanal TATA/TME: a case-matched study of taTME versus laparoscopic TME surgery for rectal cancer. Tech Coloproctol 20:467-473. doi:10.1007/s10151-016-1482-y 